\title{
Vigência do pensamento de Ortega y \\ Gasset
}

\author{
Martha García Gomensoro de Sánchez*
}

\begin{abstract}
Isto que está ai é uma onda recém-chegada de tempo novo. Sobre ela há de saltar quem quiser se salvar. Aquele que resistir, que não queira compreender a nova fisionomia que toma o viver, ficará submerso na ressaca irremediável do pretérito - em todas as ordens e em todos os sentidos - em sua obra se é intelectual ou artista, em seus amores se é sentimental, em sua política se é ambicioso ${ }^{1}$.
\end{abstract}

O conteúdo desse trecho, um dos mais significativos da obra de Ortega y Gasset, tem uma abrangência tal que poderia ser atribuído a um literato universal como Júlio Verne ou a um cientista visionário dos avanços da tecnologia como Àldous Huxley. Mas em todo caso foi Ortega quem antes e de forma completa explicitou o conceito de circunstância e apontou as suas implicações. Circunstância, diz: "é o momento existencial concreto", apóia-se na etimologia, do latim árcum-stantia - que expressa a particularidade, a delimitação, o lugar certo e preciso de cada perspectiva de mundo, de tudo quanto é a cada um externo e interno: o que está em redor. E afirma ainda: "essa circunstância envolve meu corpo e as nebulosas mais remotas, minhas disposições e vivências psíquicas e o mundo histórico social que me rodeia." ${ }^{2} \mathrm{O}$ homem assim pensado é produto da circunstância.

Freire assume o conceito orteguiano, dinâmico, de circunstância e acrescenta que à existência da circunstância soma-se a consciência da mesma, condição essa necessária para fazer do ser humano um agente de transformação. Os autores que se ocuparam de destacar esse cenário natural do homem como gerador dos fatos, além de usar o termo "circunstância" se utilizam também de um outro: "realidade". Assim encontra-se em Einstein: "devo me tornar idôneo para que a realidade visite minhas facticidades." 3 Dessa forma Einstein conduz a um conhecimento consciente da realidade, assim se estará apto a compreender os fatos, as facticidades. Todavia a palavra circunstância, como sinônimo de realidade, incorpora um outro termo: "contexto", preferido pelos cientistas sociais e que significa exatamente "tecido junto", semelhante à trama do tear onde os fios transversais passam entre os fios da urdidura. Nesse mesmo sentido Pedro Demo atenta para uma análise contextual dos fenômenos, do saber, o que significa inserir esse conhecimento no sistema considerado como um todo, para descobrir as relações que tem com outros fatos. É de importância capital para a procedência (ou não) das investigações.

\footnotetext{
* Professora do Departamento de Métodos e Técnicas do Setor de Educação da Universidade Federal do Paraná

${ }^{1}$ ORTEGA Y GASSET, J. Que é filosofia? Rio de Janeiro: Livro Ibero-Americano, p. 48.

2 ORTEGA Y GASSET, apud, MARÍAS, J. Introdução à filosofia. São Paulo: Duas Cidades, 1996, p. 43.

${ }^{3}$ EINSTEIN, Albert, apud. ROHDEN, H. Einstein, o enigma da matemática. São Paulo: Alvorada, 1981, p. 88
} 
Considerada a circunstância (realidade-contexto) como dinâmica, determinante de fatos e ao mesmo tempo por elas determinada, autores de diversas áreas têm se preocupado com a caracterização da atual circunstância, palco da virada do século.

É unânime a convicção de que o traço mais notório é o dinamismo, as mudanças, que não se medem mais em séculos, mas em dias, em horas, às vezes. Gino Germani assinala uma outra característica essencial, que é a expansão dessas mudanças, no sentido tanto geográfico como social, o que significa que abrange: todas as regiões do planeta, todos os grupos sociais e todos os indivíduos (porque os meios de comunicação e a facilidade e freqüência de todos os tipos de contato destruíram todas as antigas barreiras). E tendo como verdadeiro que esses fenômenos interferem em todos os aspectos da vida humana: organização econômica, estratificação social e familiar, sistemas políticos etc., é de interesse essencial inferir que esse impacto implica mudanças substanciais nas formas de pensar, de sentir e de comportamento. ${ }^{4}$ Isto também foi foco das reflexões filosóficas de Ortega y Gasset (1961, p. 43) que, em relação à complexidade das interferências dos fatos, explica que "por isso as mudanças históricas supõem o nascimento de um tipo de homem diverso em relação ao que havia; isto é, a supõem mudança de gerações". 5 Essa interferência toca muito fundo na questão ética da necessidade de atualização permanente do professor.

Complementando essas reflexões parece oportuno lembrar que a revolução científica propiciou também uma outra mudança: ciência passou a significar conhecimento. Então a única saída do educador diante dessa certeza, para ser operante, é organizar os conteúdos curriculares de maneira a incentivar antes a formação do que a informação. O "aprender a aprender" se levanta assim como um princípio organizador que orienta a formação ao longo da vida e - como enfatiza Vasconcellos - essa formação permanente comporta uma continuidade essencial durante a vida toda, não apenas do desenvolvimento do ser humano, mas da sua inserção construtiva na sociedade. $^{6}$

Enfocando os traços que perfilam esse final de século num evento internacional, reuniram-se cientistas do mundo inteiro em Veneza; nessa oportunidade foi produzido um documento conhecido como a Declaração de Veneza, subintitulado "A Ciência diante do limiar do conhecimento: o prólogo do nosso passado cultural". ${ }^{7}$ Mostra-se que pelo seu dinamismo o conhecimento tem chegado aos confins nos quais pode começar o diálogo com outras formas de conhecimento antes impensadas. Eis um parágrafo: "Mesmo reconhecendo as diferenças fundamentais entre a ciência e a tradição, hoje não mais se reconhece a sua oposição mas a sua complementaridade". 8 Esse reencontro inesperado e enriquecedor entre as ciências e as tradições prevê a chegada de uma nova visão da humanidade facilitada pelo aprimoramento e socialização de ciência e tecnologia, amparados pelas ciências de comunicação. Raciocínio semelhante já esteve presente no pensamento de Ortega y Gasset (1961, p. 68) que acredita: "não é possível que as ciências permaneçam nesta posição de intratável independência sem perder o que já conquistaram; é preciso que consigam articular-se umas em outras, o que não é avassalar-se". ${ }^{9}$ Estavam se explicitando os fundamentos da interdisciplinaridade.

\footnotetext{
${ }^{4}$ GERMANI, G. Política e sociedade numa época de transição. São Paulo: Mestre Jou, 1973, p. 78.

${ }^{5}$ ORTEGA Y GASSET, J., p. 43.

${ }^{6}$ VASCONCELLOS, Apud. SÁNCHEZ, M. G. G. de. O laboratório: uma alternativa de sistematização de estudos sobre currículos. Curitiba, 1983. Dissertação de Mestrado. UFPR. 70. p.

${ }^{7}$ UNESCO. Declaração de Veneza: A ciência diante do limiar do conhecimento: o prólogo do nosso passado cultural, 1986.

${ }^{8}$ UNESCO, op. cit.

${ }^{9}$ ORTEGA Y GASSER, J. p. 68.
} 
Ivani Fazenda uma das figuras mais destacadas na questão da interdisciplinaridade, a define de forma muito simples como "um trabalho em parceria". Nela reconhece uma atitude para o conhecimento que foi esquecida em algumas décadas e revisitada agora como palavra de ordem das questões educacionais, universalmente.

Mas ela insiste na exigência da atualização do professor; só assim é que acontece a produção em parceria e se transforma em ciência. E conclui que essa interdisciplinaridade faz parte do paradigma emergente do conhecimento e ao mesmo tempo ameniza um outro sinal dos tempos que e a hiperespecialização. ${ }^{10}$

À guisa de conclusão, aparece como óbvia a vigência do pensamento e a obra toda de Ortega y Gasset, sendo o seu mérito maior o fato de ter ido além das outras concepções que apontaram para a realidade circundante do ser humano como quase que exclusivamente biológica. Julián Marias, estudioso de Ortega, constata essa questão até em outras línguas (milieu em francês; environment em inglês e unwelt em alemão) e observa que estes termos foram gradativamente se estendendo a outras esferas. Já em Ortega, mostra Marias, esta concepção não tem uma significação primariamente biológica, mas humana e essencialmente histórica. ${ }^{11}$ A idéia de circunstância em Ortega y Gasset, num espectro maior, é um apelo para o gênero humano se adaptar aos novos tempos e lança a certeza de que para que alguma coisa importante mude no mundo é essencial que se mude o tipo de homem, gerando também um tipo de sensibilidade vital diferente da anterior, com seus caracteres, disposições e preferências próprios. ${ }^{12}$ Considerando que a educação interage com a circunstância, é instigante aderir à crença orteguiana de que o homem deve mudar, deve optar por esta mudança. E isto não é uma utopia!

\section{REFERÊNCIAS BIBLIOGRÁFICAS}

DECLARAÇÃO DE VENEZA. A ciência diante do limiar do conhecimento: o prólogo de nosso passado cultural. Veneza: UNESCO, 1986.

ROHDEN. Hubert. Einstein, o enigma da matemática. São Paulo: Alvorada, 1981,

FAZENDA, Ivani. Reflexões metodológicas sobre "Interdisciplinaridade, um projeto em parceria". In:_ • (org.) Metodologia da pesquisa educacional. São Paulo: Cortez, 1989.

GERMANI, Gino. Política e sociedade numa época de transição. São Paulo: Mestre Jou, 1973.

MARÍAS, Julián. Introdução à filosofia. São Paulo: Duas Cidades, 1966.

Circunstância y vocaciones. Madrid: Occidente, 1960.

ORTEGA Y GASSET, José. Que é filosofia? Rio de Janeiro: Livro Ibero Americano, 1961.

SÂNCHEZ. Martha G. G. de. O laboratório: uma alternativa de sistematização de estudos sobre currículo. Curitiba, 1983. Dissertação de Mestrado, Universidade Federal do Paraná.

\footnotetext{
${ }^{10}$ FAZENDA, I. Reflexões metodológicas sobre "Interdisciplinaridade, um projeto em parceria" In: (org.). Metodologia da pesquisa educacional,. São Paulo. Cortez, p. 152.

${ }^{11}$ MARIAS, J., Circunstancia y vocaciones. Madrid, Occident, p. 207.

${ }^{12}$ ORTEGA Y GASSET, J., p. 43.
} 